\title{
Guideline-based COPD management in a resource-limited setting - physicians' understanding, adherence and barriers: a cross-sectional survey of internal and family medicine hospital-based physicians in Nigeria
}

\author{
*Olufemi Olumuyiwa Desalu1, Cajetan C Onyedum², Adekunle O Adeoti \\ Laguhyel B Gundiri ${ }^{4}$, Joseph O Fadare ${ }^{5}, K^{2}$ hinde A Adekeye ${ }^{3}$, Kelechi D Onyeri ${ }^{6}$, \\ Ademola E Fawibe ${ }^{1}$
}

\footnotetext{
${ }^{1}$ Department of Medicine, University of Ilorin Teaching Hospital, Ilorin, Nigeria

${ }^{2}$ Department of Medicine, University of Nigeria Teaching Hospital, Ituku Ozalla, Enugu, Nigeria

'Department of Medicine, Ekiti State University Teaching Hospital, Ado-Ekiti, Nigeria

${ }^{4}$ Department of Medicine, University of Maiduguri Teaching Hospital, Maiduguri, Nigeria

Department of Medicine, Federal Medical Centre, Ido-Ekiti, Nigeria

${ }^{6}$ Department of Medicine, Federal Medical Centre, Birnin-Kebbi, Nigeria
}

Originally received 18th August 2012; resubmitted 23rd August 2012; revised 7th October 2012; further revisions 6th December 2012; accepted 18th December 2012; online 25th February 2013

\begin{abstract}
Background: Few data exist on the understanding and adherence to the Global Initiative for Chronic Obstructive Lung Disease (GOLD) guidelines in resource-limited settings, which are mostly in sub-Saharan Africa.

Objectives: To assess physicians' understanding, adherence, and barriers to implementation of GOLD guidelines in Nigeria.

Methods: A questionnaire based on the recommendations of the guidelines was self-administered by 156 physicians in departments of internal and family medicine in selected hospitals to assess physician understanding of the GOLD guidelines and barriers to its implementation. The medical records of patients with chronic obstructive pulmonary disease (COPD) were also reviewed to assess adherence to the guideline recommendations.

Results: The performance score of all physicians was $22.37 \pm 0.39$ (range $0-38$ ). Pulmonologists had the highest score (37.00 \pm 0.00$)$ while medical officers had the lowest score $(19.93 \pm 4.98)(F=10.16, d f=5, p<0.001)$. Forty one percent of physicians knew the spirometric criteria for diagnosing COPD and $26.9 \%$ could assess the severity. In clinical practice, $32 \%$ of patients had brief smoking counselling despite $70 \%$ being smokers, $24 \%$ had spirometry and $18 \%$ had assessment of severity. Almost $60 \%$ of patients were on oral aminophylline, $72 \%$ were on an inhaled long-acting $\beta_{2}$-agonist and corticosteroid combination, $2 \%$ had pulmonary rehabilitation and no patients were vaccinated. Self-reported adherence to the COPD guidelines was $23.7 \%$. Lack of familiarity (39.8\%) was cited as the most common barrier to adherence to the guidelines.

Conclusions: The understanding of GOLD guidelines is satisfactory among Nigerian doctors managing patients with COPD but the level of adherence is poor. Educational interventions are needed to improve the implementation of guideline-based management.

(C) 2013 Primary Care Respiratory Society UK. All rights reserved.

OO Desalu et al. Prim Care Respir J 2013; 22(1): 79-85

http://dx.doi.org/10.4104/pcrj.2013.00014
\end{abstract}

Keywords adherence, barriers, COPD guidelines, GOLD, management, understanding

The full version of this paper, with online appendices,

is available online at www.thepcrj.org

\section{Introduction}

Chronic obstructive pulmonary disease (COPD) is a leading cause of morbidity and mortality worldwide. The burden of the disease is

\footnotetext{
* Corresponding author: Dr Olufemi Olumuyiwa Desalu, Department of Medicine, University of llorin Teaching Hospital, PMB 1459, Ilorin, Kwara 240001, Nigeria. Tel: +2348035025771 E-mail: femuy1967@yahoo.co.uk
} 
projected to increase in coming decades due to continued exposure to risk factors and the ageing of the world's population. COPD is associated with a significant economic burden and remains a major public health problem. ' It is the fourth leading cause of chronic morbidity and mortality in the world and fifth in low income countries. ${ }^{2}$ It is projected to rank fifth by the year 2000 in terms of burden of disease and the third leading cause of death worldwide. ${ }^{2.5}$ The US National Heart, Lung, and Blood Institute and the World Health Organization established the Global Initiative for Chronic Obstructive Lung Disease (GOLD) to prepare a standard guideline for the management of COPD.' Despite the existence of guidelines for the diagnosis and management of the condition for more than 10 years, there is a wide variation in physicians' management of the condition and this may be ascribed to non-adherence to the guidelines. Adherence to COPD guidelines in clinical practice in most countries is not satisfactory. ${ }^{6.9}$ The lack of adherence to clinical guidelines may be due to several barriers, some of which are physician-related: lack of awareness, non-familiarity, outcome of expectancy, time constraints, and non-agreement with recommendation. Other barriers are patient-related, environmental, and guideline-related factors which are beyond the control of physicians. ${ }^{10} \mathrm{~A}$ good understanding of COPD guidelines by physicians is therefore imperative for good patient care. There is paucity of data on the understanding and adherence to the GOLD guidelines in resource-limited settings which are mostly in subSaharan Africa and Asia.

The objectives of this study were to assess physicians' understanding, level of adherence, and barriers to GOLD management guidelines in Nigeria.

\section{Methods}

\section{Study design}

We carried out a cross-sectional study among specialist physicians, residents, and medical officers in the departments of internal and family medicine of selected public hospitals in five of the six geographical regions of Nigeria. The study was carried out from January 2011 to June 2011.

\section{Study setting}

Nigeria is located in the West African sub-region; it is the most populous nation in Africa with a population of 160 million people. The Nigerian health system is structured into primary, secondary, and tertiary healthcare services. About $55 \%$ of the population live in rural areas while the remaining $45 \%$ live in urban areas. Health facilities (specialist and medical equipment) are inadequate in Nigeria, especially in rural areas." Most of the tertiary hospitals are located in the urban areas, of which only $29.4 \%$ have a spirometer. ${ }^{12}$

The tertiary healthcare services are provided by the university teaching hospitals, federal medical centres, state specialist hospitals, and a few private hospitals. All of the selected study sites are university teaching hospitals or federal medical centres, and they provide a combination of primary, secondary, and tertiary healthcare services. This is because they have departments of family medicine that attend to general medical conditions and also because of the poor referral system. ${ }^{11}$ COPD patients are either managed by family physicians or a pulmonologist, depending on the source of referral, patients' preference, associated comorbidity, and the severity of the disease.

\section{Sample size and selection}

Six geopolitical zones were initially selected for participation but complete patient data could only be obtained from five of the zones. One hospital in each zone was selected for the study. Selection was based on (1) the availability of a spirometer or accessibility in a nearby hospital; and (2) reasons of convenience and easy coordination by the zonal investigators (see Appendix 1 for the list of selected hospitals, available online at www.thepcrj.org).

The estimated number of physicians in all the departments of internal medicine and family medicine in the participating hospitals was 255. A maximum acceptable error of $5 \%$ and an estimated percentage level of participation of $50 \%$ with $95 \%$ confidence intervals were adopted. The calculated minimum sample size was 153.

This study was approved by the ethical review committee of Federal Medical Centre Ido-Ekiti in the South and Bernin-Kebbi in the North of the country and written consent was obtained from the participating doctors. All willing and consenting specialist physicians, residents, and medical officers working in the selected institutions were eligible to participate in the study. In this study, we defined 'residents' as doctors who had received a basic medical degree (MBBS, MBChB, or $\mathrm{MD}$ ) and are currently undergoing specialist training, while 'medical officers' are defined as doctors who had received a basic medical degree, are currently performing general medical duties and are not in specialist training. 'Specialist physicians' are doctors who have completed advanced education and clinical training in internal medicine and family medicine and are referred to as consultants.

Eligible physicians were approached and informed about the study; physicians who consented to participate in the study were requested to complete the questionnaire during their work-free period according to their own understanding of the subject. The participants were reminded about questionnaire completion after a period of one week and those who failed to return the questionnaire were excluded from the study.

\section{Survey instrument}

We used a pre-tested, self-administered structured questionnaire that was prepared using the GOLD guidelines.' For construct and content validity, the questionnaire was reviewed by two pulmonologists (OOD and CCO) - see Appendix 2 available online at www.thepcrj.org. There was $90 \%$ agreement on the 38 questions and their wording. We tested the questionnaire for face validity in a pilot study on five doctors to ascertain if the questions were acceptable and their wording well understood by the respondents. The survey instrument was used to collect physicians' sociodemographic information, location of practice, position in hospital, years of experience, and number of patients with COPD seen per month.

In assessing physicians' knowledge, the physicians were asked questions on their general knowledge of COPD. We divided the test items on the basic content of the COPD guidelines into the 
following six core competencies of the disease: (1) general knowledge of the aetiopathogenesis and pathophysiology of COPD; (2) assessment and diagnosis; (3) principles of therapy; (4) pharmacology (stable and acute exacerbations); (5) other nonpharmacological therapeutic modalities; and (6) prevention. Each question was designed to have a single correct answer. A total score, and a score for each of the six core competencies, were calculated for each participant.

In addition, questions were asked on awareness and adherence to any of the COPD guidelines, and they were asked to choose the close-ended answers and also to specify other reason(s) for nonadherence. The scores were grouped according to the level of training (resident, medical officer, and specialist) and by specialty (family medicine and internal medicine).

\section{Assessing physician practice}

In addition to testing their understanding of COPD, we also assessed physician practice in each centre. One of the investigators working in a selected hospital randomly selected 10 cases with a clinical diagnosis of COPD managed in the previous 12 months from the hospital database. A chart review was performed on selected cases to assess their compliance with recommendations of the GOLD guidelines in each centre. These recommendations were: assessment of COPD severity, spirometry diagnosis, smoking cessation therapy, use of bronchodilators, and use of inhaled corticosteroids, vaccination and pulmonary rehabilitation.

\section{Data analysis}

Statistical analysis was conducted using the Statistical Package for Social Sciences, Version 15.0 (SPSS Inc, Chicago, IL, USA), and descriptive statistics were performed to examine the physicians' general characteristics. Pearson's chi-square and Fisher's exact test were used to test the significance of categorical variables. All data are presented as mean (SD) and percentages where appropriate. The mean score and standard deviation were analysed by level of training and specialty. Analysis of variance (ANOVA) was used to compare the physicians' mean scores on COPD knowledge; $p$ values $<0.05$ were considered significant.

\section{Results}

A total of 156 physicians out of 255 completed and returned the questionnaire to the investigators (response rate $61 \%$ ). The mean age of the participating physicians was $34 \pm 5$ years and the median years of practice was 6 (interquartile range 4-10). The median number of COPD cases seen per month was 2 (interquartile range 2-5) (Table 1).

Physician knowledge and awareness of COPD guidelines The mean score of the participating physicians was $22.37 \pm 0.39$ (possible score range 0-38). Overall, pulmonologists had the highest score $(37.00 \pm 0.00)$, higher than the score by other internists $(28.50 \pm 0.58)$ and internal medicine residents $(23.10 \pm 4.32)$. Family physicians $(22.50 \pm 1.73)$ and their residents $(22.25 \pm 2.67)$ had a higher score than medical officers $(19.93 \pm 4.98)$. The variation in total mean scores for different categories of physicians ( $F=10.16 \mathrm{df}=5$ $\mathrm{p}<0.001)$ and the different components of the assessment of COPD knowledge was very significant $(p<0.05)$, except for the component
Table 1. General characteristics of the participating doctors

\begin{tabular}{ll} 
Characteristics & N (\%) \\
\hline Mean (SD) age (years) & $34(5)$ \\
\hline Year of practice* & $6(4-10)$ \\
\hline No. of COPD cases/month* & $2(2-5)$ \\
\hline Gender & $112(71.8)$ \\
\hline Male & $44(28.2)$ \\
\hline Female & \\
\hline Level of training & $47(30.1)$ \\
\hline Medical officers & $16(10.3)$ \\
\hline Residents in family medicine & $83(53.2)$ \\
\hline Residents in internal medicine & $4(2.5)$ \\
\hline Specialists in family medicine & $4(2.5)$ \\
\hline Specialists in internal medicine & $2(1.3)$ \\
\hline Pulmonologists & $60(38.5)$ \\
\hline Specialty & $94(60.3)$ \\
\hline Family physicians & $2(1.3)$ \\
\hline Internists & \\
\hline Pulmonologists & \\
\hline *Median (quartile). COPD=chronic obstructive pulmonary disease.
\end{tabular}

that assessed the prevention of COPD ( $\mathrm{F}=0.56 \mathrm{df}=5 \mathrm{p}=0.704)$. In the assessment of disease severity and diagnosis of COPD, pulmonologists had a significantly ( $F=3.49 \mathrm{df}=5 \mathrm{p}=0.005)$ higher score $(7.00 \pm 0.00)$ than family physicians $(5.50 \pm 0.58)$, other internists $(4.50 \pm 0.58)$ and medical officers (3.76 \pm 1.49$)$ (Table 2). Among the specialists, pulmonologists had the highest score in all sections of the test except the section on COPD prevention. In this study, 150 (96.2\%) of the physicians knew that symptoms and signs were not diagnostic of the condition, while $140(89.7 \%)$ knew that a combination of symptoms and an abnormal radiographic sign can assist in confirming the diagnosis of COPD. Only 64 (41.0\%) knew the spirometric criteria for diagnosing the condition, while 42 (26.9\%) knew how to assess the severity.

Ninety of the participating physicians (57.7\%) were aware of the COPD guidelines; these comprised all the pulmonologists and internists, 54 (65.1\%) internal medicine residents, two (50\%) family physicians, $22(46.6 \%)$ medical officers, and six (37.5\%) family medicine residents.

\section{Physician adherence to COPD guidelines}

We carried out a chart review of 50 patients with COPD to assess the physicians' practice and levels of implementation of the guidelines. Of the 50 patients reviewed, $35(70.0 \%)$ were smokers and 16 $(45.7 \%)$ of the smokers had received brief smoking counselling advice. Twelve (24\%) had been diagnosed by spirometry and in nine patients (18\%) COPD severity had been assessed. Sixteen patients (32.0\%) were on an oral short-acting $\beta_{2}$-agonist (SABA), 29 (58.0\%) were on oral aminophylline, and $36(72.0 \%)$ were being treated with a fixed dose combination of inhaled corticosteroid (ICS) and long-acting $\beta_{2}$-agonist (LABA). None of the COPD patients had received vaccination against respiratory infections. Pulmonary 


\begin{tabular}{|c|c|c|c|c|c|c|c|}
\hline $\begin{array}{l}\text { Physician } \\
\text { factors }\end{array}$ & $\begin{array}{l}\text { Pathogenesis/ } \\
\text { physiology }\end{array}$ & $\begin{array}{l}\text { Assessment } \\
\text { and diagnosis }\end{array}$ & $\begin{array}{l}\text { Principle } \\
\text { of therapy }\end{array}$ & Pharmacology & $\begin{array}{l}\text { Other } \\
\text { modalities }\end{array}$ & Prevention & Total \\
\hline No. of questions per section & 8 & 8 & 4 & 10 & 6 & 2 & 38 \\
\hline $\begin{array}{l}\text { Total mean score } \\
\text { expressed in \% }\end{array}$ & $66.00 \pm 19.00$ & $53.0 \pm 14.30$ & $62.00 \pm 29.00$ & $59.00 \pm 20.00$ & $52.00 \pm 24.83$ & $89.00 \pm 28.90$ & $59.00 \pm 12.86$ \\
\hline Total mean score & $5.27 \pm 1.49$ & $4.21 \pm 1.42$ & $2.46 \pm 1.18$ & $5.89 \pm 2.08$ & $3.09 \pm 1.50$ & $1.78 \pm 0.58$ & $22.37 \pm 0.39$ \\
\hline Medical officers & $4.40 \pm 1.56$ & $3.76 \pm 1.49$ & $2.04 \pm 1.23$ & $5.12 \pm 2.21$ & $3.06 \pm 1.51$ & $1.73 \pm 0.69$ & $19.93 \pm 4.98$ \\
\hline Residents in FM & $5.31 \pm 1.01$ & $4.38 \pm 1.26$ & $2.63 \pm 0.72$ & $6.00 \pm 1.71$ & $2.75 \pm 1.34$ & $1.63 \pm 0.50$ & $22.25 \pm 2.67$ \\
\hline Residents in IM & $5.63 \pm 1.32$ & $4.28 \pm 1.39$ & $2.65 \pm 1.18$ & $6.08 \pm 1.91$ & $3.06 \pm 1.47$ & $1.80 \pm 0.58$ & $23.10 \pm 4.32$ \\
\hline Specialists (FM) & $5.00 \pm 0.00$ & $5.50 \pm 0.58$ & $1.50 \pm 0.58$ & $6.00 \pm 2.31$ & $2.50 \pm 1.73$ & $2.00 \pm 0.00$ & $22.50 \pm 1.73$ \\
\hline Specialists (IM) & $6.50 \pm 0.58$ & $4.50 \pm 0.58$ & $3.00 \pm 0.00$ & $8.00 \pm 0.00$ & $4.50 \pm 0.58$ & $2.00 \pm 0.00$ & $28.50 \pm 0.58$ \\
\hline Specialists (Pulm) & $8.00 \pm 0.00$ & $7.00 \pm 0.00$ & $4.00 \pm 0.00$ & $10.00 \pm 0.00$ & $6.00 \pm 0.00$ & $2.00 \pm 0.00$ & $37.00 \pm 0.00$ \\
\hline$p$ values & $<0.001$ & 0.005 & 0.008 & 0.001 & 0.025 & 0.704 & $<0.001$ \\
\hline
\end{tabular}

\begin{tabular}{|c|c|c|}
\hline Recommendations & $\mathrm{N}=50$ & Implementation (\%) \\
\hline Spirometry performed & 12 & 24 \\
\hline Assessment of severity & 9 & 18 \\
\hline \multicolumn{3}{|l|}{ Smoking cessation modalities } \\
\hline Brief intervention & 16 & 32 \\
\hline Nicotine replacement therapy & 0 & 0 \\
\hline \multicolumn{3}{|l|}{ Medications } \\
\hline Oral short-acting $\beta$ agonist & 16 & 32 \\
\hline Oral aminophylline & 29 & 58 \\
\hline Inhaled corticosteroids & 36 & 72 \\
\hline Inhaled long-acting $\beta$ agonist & 36 & 72 \\
\hline Vaccinations & 0 & 0 \\
\hline Pulmonary rehabilitation & 1 & 2 \\
\hline \multicolumn{3}{|c|}{$\begin{array}{l}\text { Inhaled corticosteroids as a fixed dose combination with inhaled } \\
\text { long-acting } \beta_{2} \text {-agonist. }\end{array}$} \\
\hline \multicolumn{3}{|c|}{ COPD=chronic obstructive pulmonary disease. } \\
\hline
\end{tabular}

rehabilitation was recommended in one patient (2.0\%) (Table 3). A total of 37 participants $(23.7 \%)$ self-reported adherence to the COPD guidelines. Reported adherence was $50 \%$ in pulmonologists and internists and $0 \%$ among family physicians.

\section{Barriers to guideline adherence}

The leading barriers to the non-adherence to the COPD guidelines were lack of familiarity (39.8\%), lack of awareness (23.1\%), and lack of time (19.2\%). Twenty-two participants (14.1\%) cited disagreement with the guidelines as a barrriers to non-adherence (Figure 1).

\section{Discussion}

\section{Main findings}

The results of our study show that the participating physicians had a satisfactory understanding of the COPD guidelines. The pulmonologists had a significantly higher level of understanding
Figure 1. Barriers to COPD guideline

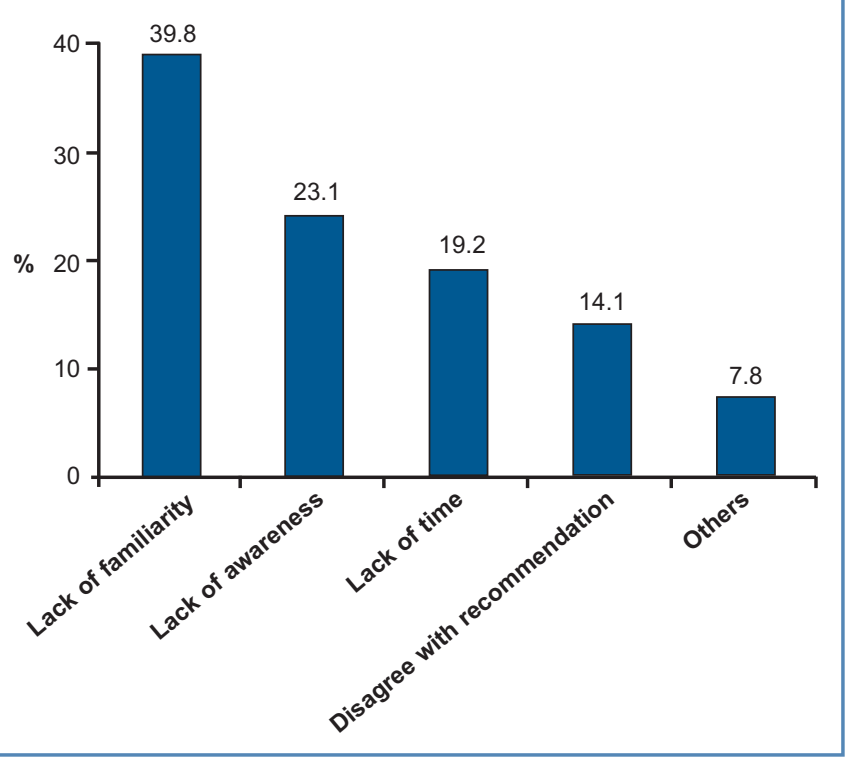

than any other category of physicians, while medical officers had the lowest level of understanding. In addition, physicians working in an internal medicine department had a significantly better understanding of the guidelines than those working in a family medicine department. The performance of the physicians also increased with their level of training, with specialists performing better than residents in each specialty. Forty-one percent of the physicians knew the spirometric criteria for the diagnosis of the condition and $26.9 \%$ knew how to assess the severity of the disease. About one-third of COPD patients reviewed had the diagnosis confirmed by spirometry. The majority of the patients were on inhaled bronchodilators and oral theophyllines. About half of the smokers among this cohort were offered some form of tobacco cessation therapy in the form of smoking counselling advice. Two percent had pulmonary rehabilitation and none of the patients was vaccinated. Lack of familiarity with the guideline and lack of 
awareness were the most important barriers to COPD guidelinebased management.

\section{Interpretation of findings in relation to previously published work}

COPD has already passed cerebrovascular disease to become the third leading cause of death in the USA. ${ }^{13}$ Almost $90 \%$ of COPD deaths occur in low and middle income countries. ${ }^{14}$ In these countries, national health expenditure is generally low and the financial and human resources are lacking and are primarily devoted to infectious diseases. Political commitment and resources are also lacking, and the allocation of a budget and human resources for the prevention and management of COPD is not a priority. ${ }^{15,16}$

Several guidelines have been developed to assist physicians and patient decisions about appropriate healthcare to achieve the goals of therapy. Every physician treating COPD patients must be aware of the guideline recommendations and incorporate them in their dayto-day practice to reduce the burden of this preventable disease.

In assessing the physicians' understanding of the guidelines, our results show that the pulmonologists had the highest knowledge score while family medicine residents and medical officers had the lowest score. We also observed that the performance of physicians increased with their level of training, as specialists tended to perform better than residents in each specialty. This result is similar to two other studies which showed that, across diverse regions of the world, the majority of medical officers had a very limited knowledge of COPD and its management compared with the other categories of doctors. ${ }^{17,18}$ The trend observed might be a reflection of the frequent exposure of more senior doctors to the recommendations of the guidelines from several sources of continuing medical education (CME) and publications.

We also evaluated the ability of physicians to assess the severity and monitor the progression of the condition. Almost one-third (26.9\%) of the physicians knew how to assess the severity of COPD. Apart from the pulmonologists who recorded 100\%, fewer than $35 \%$ of all the other categories of physicians knew how to assess COPD severity. In a study carried out in Germany, $80 \%$ of pulmonologists and $60 \%$ of primary care physicians knew the correct spirometric criteria for classifying severity. ${ }^{1920}$ In this study, all the pulmonologists and internists, $65 \%$ of internal medicine residents, $50 \%$ of family physicians, and $37.5 \%$ of family medicine residents were aware of the COPD guidelines. Awareness was lower among the family physicians, very similar to the figure of $54 \%$ in the USA. ${ }^{21}$

We also conducted a retrospective analysis of the medical records of 50 patients with COPD to determine objectively the level of implementation of the COPD guidelines. We discovered that spirometry was performed in fewer than one-third of patients for confirmation of the diagnosis. The low utilisation of spirometry in our study is close to the $23.4 \%$ reported by pulmonologists in Argentina $^{22}$ and lower than $56 \%$ in a study in Canada, ${ }^{9} 60 \%$ in the USA $_{1}{ }^{8}$ and $45-71 \%$ in Belgium and Switzerland. ${ }^{23,24}$ The poor utilisation of spirometry is perhaps responsible for the low level of severity assessment (18\%), as it is used to confirm airflow limitation that is not fully reversible and is an important parameter for assessment of disease severity. ${ }^{1,2}$ The level of disease severity assessment found in our study (18\%) is similar to that in a study in Devon, UK. ${ }^{25}$ Lack of knowledge of spirometry interpretation may also be associated with the low utilisation as only one-quarter $(26.9 \%)$ of the respondents could correctly make a spirometric diagnosis of COPD.

In this study approximately half of the smokers were offered tobacco cessation therapy in the form of smoking counselling advice. Nicotine replacement therapy (NRT) was not offered to any of the patients. This result is similar to $35-45 \%$ in Belgium ${ }_{1}^{24}$ but lower than Switzerland $(69 \%),{ }^{23}$ the UK $(75 \%),{ }^{25}$ and Canada $(95 \%) .{ }^{9}$ In a study to evaluate the knowledge and practices of smoking cessation among physicians in Nigeria, Desalu et al. ${ }^{26}$ found that $61.5 \%$ received brief advice/counselling ( $2-5 \mathrm{~min})$ and $3.7 \%$ used NRT. We are not surprised at the provision of smoking counselling as the only means of intervention as this may be due to poor knowledge of tobacco cessation among Nigerian physicians. ${ }^{26}$ This result has highlighted the need to increase knowledge of smoking cessation among Nigerian doctors.

Most of the patients (72\%) were on a fixed dose ICS/LABA combination inhaler, and $58 \%$ were on oral aminophylline. The high rate of utilisation of LABAIICS fixed dose combinations is due to the fact that uncombined forms of ICS are no longer available - since beclomethasone and budesonide have been withdrawn from the market by the pharmaceutical companies. Most patients with mild disease may therefore have been unduly treated with LABA and ICS combination. Further stratification of the prescription pattern according to physician specialty was not possible as most of this information was missing due to the retrospective collection of the data. This drawback might be a justification for a future study to compare the prescription pattern of COPD medications by level of training and specialty.

Pulmonary rehabilitation was offered to only $2 \%$ of the patients reviewed, which is similar to findings in previous studies in which only a small proportion of patients were offered pulmonary rehabilitation..$^{9,23,27}$ This in contrast to a study by Sivori et al. regarding COPD diagnosis and treatment by chest physicians. ${ }^{22}$ The very low utilisation of pulmonary rehabilitation may be attributed to lack of human resources including specialists in pulmonary rehabilitation, infrastructure, and establishment of a well-equipped pulmonary rehabilitation unit in most hospitals in Nigeria. The pulmonary rehabilitation components should include exercise training, selfmanagement education, psychosocial and nutritional interventions, and GOLD guidelines. The potential benefits of pulmonary rehabilitation include reduction of respiratory symptoms, decreased disability, and increased participation in physical and social activities. Pulmonary rehabilitation is now an evidence-based therapy that should be available to all patients with symptomatic COPD or who have decreased functional status despite optimal medical treatment. ${ }^{1}$

None of the patients received vaccination, which is in contrast to other studies.2,27 The lack of implementation of vaccination in this study may be due to poor awareness of its impact on the outcome of management, non-availability, and affordability of the vaccines, 
considering the fact we are operating in a resource-poor setting. Influenza vaccines can reduce serious illness and death in patients by $50 \%{ }^{28,29}$ According to the guidelines, pneumococcal polysaccharide vaccine is recommended for COPD patients aged 65 years and older and for COPD patients younger than 65 years with a forced expiratory volume in 1 second $<40 \%$ predicted. ${ }^{1.30,31}$

Several factors were found to be responsible for nonimplementation of some recommendations of the guidelines. The most important were lack of familiarity and lack of awareness. This observation was similar to findings from other studies. ${ }^{6,32}$

\section{Strengths and limitations of this study}

This study was limited by the retrospective nature of the data collected from patients' records, which is characterised by missing information. Despite this limitation, we have been able to assess the understanding, adherence in clinical practice, and barriers to the implementation of the GOLD guidelines in Nigeria among all categories of medical doctors treating COPD in hospitals in Nigeria, with representation from most of the country's regions. Our findings may be similar to those in other resource-poor or resourcemismanaged countries in sub-Saharan Africa and Asia.

Implications for future research, policy and practice

Our study will serve as a baseline for future research on the audit of COPD care in all categories of healthcare systems in Nigeria (academic, public, and private). The results of this study will also serve as a wake-up call to the National Thoracic Society, other stakeholders in the healthcare industry, and policy makers, to adopt a pragmatic approach to the management of COPD.

\section{Conclusions}

Understanding of the GOLD COPD guidelines among physicians in Nigeria is satisfactory, whilst adherence to most of the guideline recommendations is very poor. We recommend that the World Spirometry Day should be used to increase the awareness and use of spirometry, which is fundamental for assessing COPD severity. Awareness of smoking cessation therapy and pulmonary rehabilitation should also be increased among physicians by organising more continuing medical education (CME) on these modalities of therapy. Physicians should collaborate with hospital authorities to establish smoking cessation teams and pulmonary rehabilitation units. The pharmaceutical industry can also contribute by making available cheaper vaccines for COPD patients. The results of this study have highlighted the need to address factors that negatively affect, and barriers to the implementation of, guidelinebased clinical practice. Educational interventions are required to achieve optimal care for COPD patients.

\section{Handling editor Niels Chavannes \\ Statistical review Gopal Netuveli}

Acknowledgements The authors thank the residents who took part in the study for spending their valuable time in answering the questionnaire, and also the health record officers in participating hospitals who assisted the investigators in retrieving the medical files of cases with a clinical diagnosis of COPD.

Conflicts of interest The authors declare that they have no conflicts of interest in relation to this article.

Contributorship OOD conceived and designed the study, conducted data collection and analysis, wrote the first draft, and contributed to the final draft of the manuscript. CCO and AOA designed the study, conducted data collection, and reviewed the final draft of the manuscript. LG, KAA, and KDO conducted data collection and contributed to the final draft of the manuscript. JOF conducted data collection and reviewed the final draft of the manuscript. AEF contributed to the first and final drafts of the manuscript.

Funding The study was funded by the authors.

\section{References}

1. Global Initiative for Chronic Obstructive Lung Disease. Global strategy for the diagnosis, management, and prevention of chronic obstructive pulmonary disease (updated 2010). Available at: www.copdgold.org

2. World Health Organization. The global burden of disease: 2004 update. Geneva: World Health Organization, 2008.

3. Murray CJL, Lopez AD, eds. The global burden of disease: a comprehensive assessment of mortality and disability from diseases, injuries and risk factors in 1990 and projected to 2020. Cambridge: Harvard School of Public Health on behalf of the World Health Organization and the World Bank, 1996.

4. Murray CJ, Lopez AD. Alternative projections of mortality and disability by cause 1990-2020: Global Burden of Disease Study. Lancet 1997;349(9064):1498-504. http://dx.doi.org/10.1016/S0140-6736(96)07492-2

5. Lopez AD, Shibuya K, Rao C, et al. Chronic obstructive pulmonary disease: current burden and future projections. Eur Respir J 2006;27:397-412. http://dx.doi.org/ 10.1183/09031936.06.00025805

6. Yawn BP, Wollan PC. Knowledge and attitudes of family physicians coming to COPD continuing medical education. Int J Chron Obstruct Pulmon Dis 2008;3:311-17.

7. Harvey PA, Murphy MC, Dornom E, Berlowitz DJ, Lim WK, Jackson B. Implementing evidence-based guidelines: inpatient management of chronic obstructive pulmonary disease. Intern Med J 2005;35:151-5. http://dx.doi.org/10.1111/j.14455994.2004.00754.x

8. Chavez PC, Shokar NK. Diagnosis and management of chronic obstructive pulmonary disease (COPD) in a primary care clinic. COPD 2009;6:446-51. http://dx.doi.org/10.3109/15412550903341455

9. Bourbeau J, Sebaldt RJ, Day A, et al. Practice patterns in the management of chronic obstructive pulmonary disease in primary practice: the CAGE study. Can Respir $J$ 2008;15:13-19

10. Cabana MD, Rand CS, Powe NR, et al. Why don't physicians follow clinical practice guidelines? A framework for improvement. JAMA 1999;282:1458-65. http://dx.doi.org/10.1001/jama.282.15.1458

11. Omoruan Al, Bamidele AP, Phillips OF. Social health insurance and sustainable healthcare reform in Nigeria. Ethno Med 2009;3:105-10.

12. Desalu OO, Onyedum CC, Salawu FK, Iseh KR, Salami AK. Asthma in Nigeria: are the resources available to support internationally endorsed standards of care? Health Policy 2011;99:250-4. http://dx.doi.org/10.1016/j.healthpol.2010.10.006

13. Miniño AM, Xu J, Kochanek KD. Deaths: preliminary data for 2008. National Vital Statistics Reports. Hyattsville, MD: National Center for Health Statistics, 2010.

14. World Health Organization. Global status report on non-communicable diseases Geneva: World Health Organization, 2010.

15. Aït-Khaled N, Enarson DA, Chiang C-Y. COPD management. Part II. Relevance for resource-poor settings. Int J Tuberc Lung Dis 2008;12(6):595-600.

16. World Health Organization. National health accounts: country information. Geneva, Switzerland: WHO, 2007. http://www.who.int/nha/country (accessed March 2008).

17. Aisanov Z, Bai C, Bauerle O, Colodenco FD, et al. Primary care physician perceptions on the diagnosis and management of chronic obstructive pulmonary disease in diverse regions of the world. Int J Chron Obstruct Pulmon Dis 2012;7:271-82.

18. Salinas GD, Williamson JC, Kalhan R, et al. Barriers to adherence to chronic obstructive pulmonary disease guidelines by primary care physicians. Int J Chron Obstruct Pulmon Dis 2011;6:171-9. http://dx.doi.org/10.2147/COPD.S16396

19. Glaab T, Banik N, Singer C, Wencker M. Guideline conformance for outpatient management of COPD. Dtsch Med Wochenschr 2006;131:1203-8. http://dx.doi.org/10.1055/s-2006-941752

20. Glaab T, Banik N, Trautmann M, Hellmann A, Wencker M. Guideline-conformity of outpatient COPD management by pneumologists. Pneumologie 2006;60:395-400. http://dx.doi.org/10.1055/s-2006-932166

21. Barr RG, Celli BR, Martinez FJ, et al. Physician and patient perceptions in COPD: the COPD Resource Network Needs Assessment Survey. Am J Med 2005;118:1415. http://dx.doi.org/10.1016/j.amjmed.2005.07.059 
22. Sivori ML, Raimondi GA. Survey of chest physicians regarding COPD diagnosis and treatment. Medicina (B Aires) 2004;64:113-19.

23. Fritsch $K$, Jacot $M-L$, Klarer $A$, et al. Adherence to the Swiss guidelines for management of COPD: experience of a Swiss teaching hospital. Swiss Med Wkly 2005;135:116-21

24. Decramer M, Bartsch P, Pauwels R, Yernault JC. Management of COPD according to guidelines. A national survey among Belgian physicians. Monaldi Arch Chest Dis 2003; 59:62-80.

25. Jones RC, Dickson-Spillmann M, Mather MJ, Marks D, Shackell BS. Accuracy of diagnostic registers and management of chronic obstructive pulmonary disease: the Devon primary care audit. Respir Res 2008;9:62. http://dx.doi.org/10.1186/14659921-9-62

26. Desalu OO, Adekoya AO, Elegbede AO, Dosunmu A, Kolawole TF, Nwogu KC. Knowledge of and practices related to smoking cessation among physicians in Nigeria. J Braz Pneumol 2009;35:1198-203. http://dx.doi.org/10.1590/S180637132009001200006

27. Rutschmann OT, Janssens JP, Vermeulen B, Sarasin FP. Knowledge of guidelines for the management of COPD: a survey of primary care physicians. Respir Med
2004;98(1):932-7. http://dx.doi.org/10.1016/j.rmed.2004.03.018

28. Wongsurakiat P, Maranetra KN, Wasi C, Kositanont U, Dejsomritrutai W, Charoenratanakul S. Acute respiratory illness in patients with COPD and the effectiveness of influenza vaccination: a randomized controlled study. Chest 2004;125:2011-20. http://dx.doi.org/10.1378/chest.125.6.2011

29. Wongsurakiat P, Lertakyamanee J, Maranetra KN, Jongriratanakul S, Sangkaew S Economic evaluation of influenza vaccination in Thai chronic obstructive pulmonary disease patients. J Med Assoc Thai 2003;86:497-508

30. Jackson LA, Neuzil KM, Yu O, et al. Effectiveness of pneumococcal polysaccharide vaccine in older adults. N Engl J Med 2003;348:1747-55. http://dx.doi.org/ 10.1056/NEJMoa022678

31. Alfageme I, Vazquez $R$, Reyes $N$, et al. Clinical efficacy of anti-pneumococcal vaccination in patients with COPD. Thorax 2006;61:189-95. http://dx.doi.org/10.1136/thx.2005.043323

32. Perez X, Wisnivesky JP, Lurslurchachai L, Kleinman LC, Kronish IM. Barriers to adherence to COPD guidelines among primary care providers. Respir Med 2012;106:374-8. http://dx.doi.org/10.1016/j.rmed.2011.09.010

\section{Available online at http://www.thepcrj.org}


OO Desalu et al.

Appendix 1.

University of Ilorin Teaching Hospital, Ilorin

University of Nigeria Teaching Hospital, Ituku Ozalla, Enugu

Federal Medical Centre, Ido-Ekiti

University of Maiduguri Teaching Hospital, Maiduguri

Federal Medical Centre, Birnin-Kebbi 
COPD GUIDELINES: PHYSICIANS UNDERSTANDING, ADHERENCE

AND BARRIERS IN TERTIARY HOSPITALS IN NIGERIA. INFORMATION SHEET

WHAT IS THE STUDY ABOUT

The study aims at testing the internist and family physicians understanding, practice and barriers to COPD guidelines in tertiary hospitals in Nigeria. To develop appropriate educational interventions that address areas of physician misunderstanding, it is important to identify these components. WHAT IS EXPECTED OF YOU IF YOU AGREE TO PARTICIPATE

1. It is expected that those who agree to participate will answer questions face to face using a questionnaire.

YOUR PARTICIPATION IS VOLUNTARY\& CONFIDENTIALITY Your participation is voluntary and you may withdraw at any phase of the study. I hereby give consent to participate in the study Sign/thumb print Date.

Please answer the questions by ticking the box or circling the $T$ or $\mathrm{F}$ after your chosen response
A. Demographic data: Age:
Sex: $M$ / F Years of practice:

Current position in your hospital: SHO /medical officer / Resident

Consultant

Others (specify)

Which types of hospital are you currently employed?

Teaching Hosp / FMC/Specialist / District \& General Hosp

Where is the location of your hospital? Urban area / rural area

What is the average estimate of COPD patients you see per month? 


\section{SECTION 1: Classification and aetiopathogenesis}

1. COPD is a chronic inflammatory disease due to noxious particle and gases and is characterized by progressive airflow limitation that fully is reversible $T / F$

2. Which of the following is not a Risk factors for COPD :

Passive Tobacco smoke

Occupational dust exposure

Indoor pollution from biomass fuel.

Rhinitis

Ageing

Low socioeconomic status and poor nutrition

$\mathrm{T} / \mathrm{F}$

3. COPD is preventable, treatable and progressive disease $T / F$

4. With best of care lung function does not decline over time $T / F$

5. The following pathologies are present in COPD except:

Alveolar wall destruction

Loss of elasticity and loss of elastic recoil

Increased inflammatory cell: eosinophilic and mast cell

Airway remodeling

Pulmonary hypertension

6. COPD is not reversible either spontaneously or with treatment $T / F$

7. Extrapulmonary manifestations are uncommon in COPD $T / F$

8. COPD exacerbations are always commonly caused by klebsiella and pseudomonas Infection $T / F$

\section{SECTION 2: ASSESMENT, SEVERITY AND DIAGNOSIS}

9. A clinical diagnosis of COPD may be entertained with a complaint of chronic cough plus chronic sputum production or progressive dyspnoea with a history of cigarette smoking. $T$ / $F$

10. Chronic cough and sputum expectoration is always diagnostic of COPD T / F

11. Which of the following data sets is most diagnostic of COPD as a primary diagnosis? (Each value FEV1 \&FVC is a \% predicted) 
Appendix 2.

$\begin{array}{lcc}\text { FEV1 } & \text { FVC } & \text { post-bronchodilator FEV1/FVC } \\ 80 & 85 & 78 \\ 65 & 70 & 64 \\ 69 & 67 & 80 \\ 56 & 80 & 72\end{array}$

12. A 65 year old lorry driver complaint of cough of 3 years associated sputum expectoration; He has history of 23 pack years of cigarette smoking. The FEVI/FVC was $<70 \%$ and FEVI was $55 \%$. Which stage of COPD will you classify this patient?

Stage 1

Stage 2

Stage 3

Stage 4

13. Patients physical sign like hyperinflation and abnormal chest radiograph can help to confirm the diagnosis of a COPD $T$ / $F$

14. Arterial blood gas measurements are routinely required in COPD diagnosis $T / F$

15. Measurement of lung volume is recommended during exacerbation to determine the severity of illness T/ F

16. In Adult below 45 years, the screening for one of the following is helpful in the diagnosis of COPD

a. alpha anti-trypsin deficiency

b. cigarette smoke

c. carbon monoxide diffusing capacity DLCO

d. Rheumatoid factor

SECTION 3: PRINCIPLE OF THERAPY OF STABLE COPD

17. The goal of COPD treatment are to achieve the followings except

a) Relieve symptoms

b) Prevent disease progression

c) Improve exercise tolerance

d) Control or cure

e) Prevent and treat complications and exacerbation

18. The management of stable COPD requires stepwise treatment like asthma $T$ / $F$

19. Dry Powder Inhalers (DPI) requires higher inspiratory flow rates 
than metered dose inhalers (MDI). $T$ / F

20. The use of a spacer (holding chamber) improves drug delivery, increases lung deposition, and may reduce local and systemic side effects $T / F$

SECTION 4:

PHARMACOTHERAPY OF STABLE COPD

21. Inhaled Long-acting inhaled_ $B_{2}$-agonists are more effective and convenient than short acting $\mathrm{B}_{2}$-agonists in stable COPD $T / F$

22.Long-acting inhaled_ $B_{2}$-agonists should be used as monotherapy in COPD as these medications appear to influence the airway inflammation $T$ / $F$

23. Low dose theophyllines is weak and they are less effective than a low dose of inhaled glucocorticosteroids in decreasing the long term decline in lung function $T / F$

24. As add-on therapy to anti-cholinergics, theophylline is more effective than using long-acting inhaled $B_{2}$-agonists alone in stable COPD $T$ / $F$

25. Which of the following medication is recommended for stable COPD
a) Mucolytics
b) Cough syrups
c) Antibiotics
d) vitamins $E \& C$
e) None of the above

26. Prolonged inhaled glucocorticosteroids in COPD is recommended to patient in
a) Stage 1
b) Stage 2
c) Stage $3 \& 4$

\section{PHARMACOTHERAPY OF ACUTE EXACERBATION}

27. Inhaled short acting $B_{2}$-agonists is the preferred drug of choice for acute exacerbation of COPD $T / F$

28. Oral or IV glucocorticosteroids is recommended for acute exacerbation COPD $T / F$

29. Theophylline is the second line drug in acute exacerbation in COPD. T / F

30. Antibiotics are not routinely required unless there are signs of 
pneumonia, purulent and increased sputum production if patient is on mechanical ventilator $T / F$

SECTION 5: OTHER THERAPY

31.Pulmonary rehabilitation is indicated only in stage 3 to 4 COPD $T / F$

32. It is a good idea to give Vaccinations to all COPD patients. $T$ / $F$

33. Surgery is often beneficial in most COPD patients $T / F$

$34.100 \%$ O2 $(7-10 \mathrm{~L} / \mathrm{min})$ is required for hypoxia in acute exacerbation of COPD $T$ / $F$

35. Long term $O 2$ therapy is indicated in COPD Except

a) $\mathrm{SaO} 2<88$ or $\mathrm{PaO} 2<55 \mathrm{mmh} \pm$ hypercapnia

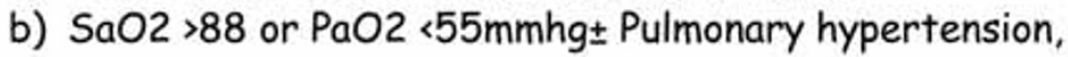
$P C V>55 \%$,

c) peripheral oedema and RVF

d) $\mathrm{FEV} 1=70 \%$ Predicted

36. Venturi mask is not effective than nasal prong/canula in delivering controlled Oxygen in COPD T/ F

SECTION 6: PREVENTION

37. Avoiding or controlling the risk factors after the development of COPD are not necessary $T / F$

38. Tobacco cessation therapy does not have a significant role in the management of COPD once the lung is damaged $T / F$

ADHERENCE TO GIUDELINE

39. Are you aware of any COPD protocol or guideline(s) yes / no

40.Do you adhere to the COPD protocol or guideline(s) yes / no

BARRIERS TO ADHERENCE

41. If response to $Q 40$ is no tick the reason(s) for non adherence note (multiple responses are allowed)

- Disagree with the recommendation of guideline

- Lack of Awareness

- Lack of Familiarity of its recommendation

- Lack of educational material /support

- Lengthy and difficult to remember

- Lack of time

- Lack of equipment and resources (spirometry, cessation expert).

- Believed he/she cannot adhere to guideline recommendation

- Believed guideline will not improve the outcome of COPD 
Oo Desalu et al.

Appendix 2.

- Lack of motivation \& Poor dissemination by physician to colleagues

- Others (specify) 